\title{
EFICIÊNCIA E PRINCÍPIO DE FUNCIONAMENTO DE BARREIRA FÍSICA CÔNICA CONTRA AS QUENQUÉNS
}

\author{
Josie Tatiane Santos de Almeida ${ }^{1}$, Leonardo Oliveira Medici ${ }^{2}$, Elen de Lima Aguiar-Menezes ${ }^{3}$ \\ ${ }^{1}$ Eng ${ }^{\text {a }}$. Florestal, Mestranda em Fitossanidade e Biotecnologia Aplicada, UFRRJ, Seropédica, RJ, Brasil - josie_almeida@yahoo.com.br \\ ${ }^{2}$ Eng. Agrônomo, Dr., Depto. de Ciências Fisiológicas, UFRRJ, Seropédica, RJ, Brasil - lomedici@ufrrj.br \\ ${ }^{3}$ Eng $^{\mathrm{a}}$. Agrônoma, Dr ${ }^{\mathrm{a}}$., Depto. de Entomologia e Fitopatologia, UFRRJ, Seropédica, RJ, Brasil - emenezes@ufrrj.br \\ Recebido para publicação: 29/01/2012 - Aceito para publicação: 06/09/2013
}

\begin{abstract}
Resumo
As formigas cortadeiras são importantes pragas agrícolas e florestais e podem ser controladas por diferentes métodos, entre os quais as barreiras físicas que impedem o acesso dessas formigas à planta. Objetivou-se avaliar a eficiência e o princípio de funcionamento de cones de lâmina de acetato em dois tamanhos de geratriz como barreiras físicas contra essas pragas. Dois experimentos foram conduzidos em quintal residencial em Petrópolis, RJ. Um dos experimento, usando pedaço de casca de laranja como isca atrativa para essas formigas, consistiu de três tratamentos: isca protegida com cone de 5,4 ou $10,8 \mathrm{~cm}$ de geratriz e isca sem cone (controle) (dez repetições/tratamento). No outro experimento, esses cones foram colocados em uma raiz de Araceae para conter intenso fluxo de formigas. Identificaram-se duas espécies de quenquéns: Acromyrmex niger (F. Smith) e Acromyrmex disciger (Mayr). Duas iscas foram cortadas pelas quenquéns quando protegidas pelo cone pequeno, nenhuma pelo cone grande e todas as iscas foram cortadas no controle. O fluxo das quenquéns na raiz foi contido pelo cone pequeno por apenas 10 minutos, enquanto que o cone grande o conteve durante as 3 horas de observação. A tendência das quenquéns em explorar preferencialmente a borda do cone pode explicar o seu funcionamento.

Palavras-chave: Formicidae; Myrmicinae; Attini; barreira antiformiga; controle mecânico.
\end{abstract}

\begin{abstract}
The efficiency and working principle of conical physical barrier against the leaf-cutting ants. The leafcutting ants are important agricultural and forest pests and may be controlled by different methods. Among them, the physical barriers that prevent the access of these ants to the plants. The present work aimed to evaluate the efficiency and the working principle of cones of acetate foil at two generatrix sizes as physical barriers against these pests. We conducted two experiments in home garden in the municipality of Petropolis, RJ. An experiment used slice of orange peel as attractant bait for leaf-cutting ants and three treatments: bait protected with cone of 5.4 or $10.8 \mathrm{~cm}$ of generatrix, and bait without cone (control) (ten replicates/treatment). In another experiment, we placed these cones on a root of Araceae in order to control the intense flow of ants. It was identified two species of leaf-cutting ants: Acromyrmex niger (F. Smith) and Acromyrmex disciger (Mayr). The leaf-cutting cut two baits protected by the small cone, none of the baits protected by the big cone, and cut all the baits in control. The flow of the leafcutting ants on the root was controlled by the small cone during only 10 minutes, while the big cone controlled the flow during the 3 hours of observation. The tendency of the leaf-cutting ants to explore preferentially the edge of the cone may explain its operation.

Keywords: Formicidae; Myrmicinae; Attini; anti-ant barrier; mechanical control.
\end{abstract}

\section{INTRODUÇÃO}

As quenquéns, juntamente com as saúvas, representam as chamadas formigas-cortadeiras e pertencem aos gêneros Acromyrmex Mayr e Atta Fabricius, respectivamente. Essas formigas constituem pragas-chave de diversas culturas agrícolas e florestais (ANTUNES; DELLA LÚCIA, 1999; JACCOUD, 2000; ZANETTI et al., 2003). Os estudos direcionados às espécies do gênero Acromyrmex são escassos em comparação às do gênero Atta, porém as quenquéns vêm ocupando cada vez mais lugar de destaque em áreas de reflorestamento, visto que, por vezes, sua abundância supera à das saúvas, causando danos 
significativos (ANTUNES; DELLA LÚCIA, 1999; LINK et al., 2000; NICKELE et al., 2009). Em plantios de eucalipto, por exemplo, as quenquéns são capazes de causar até $30 \%$ de perdas quando seu nível de infestação chega a 200 formigueiros/ha (MENDES FILHO, 1981), enquanto que, em áreas recém-plantadas de Pinus taeda L., Acromyrmex crassispinus (Forel) pode causar de 50 a $100 \%$ de desfolha, incluindo o corte do meristema apical (NICKELE, 2008).

O método químico tem sido a forma sistemática e tradicional de controle das formigascortadeiras (BOARETTO; FORTI, 1997; JACCOUD, 2000; LINK et al., 2000). Retratando a dimensão do uso, Boaretto e Forti (1997) mencionaram que o Brasil consome em torno de 12.000 t de iscas granuladas tóxicas por ano, que é a forma mais comumente utilizada no controle dessas formigas. Embora o método químico seja considerado prático e eficiente, tem alto custo operacional e é inconveniente devido à falta de especificidade, contaminação do meio ambiente e toxicidade para o aplicador (SOUZASILVA et al., 2005). Ademais, em relação ao controle de algumas espécies de Acromyrmex, a aplicação de formicidas de forma localizada é dificultada, visto que as quenquéns têm o hábito de forragear à noite, não deixam trilha como as saúvas e seus ninhos são difíceis de localizar se não estão acompanhados por montículos de terra (SOUSA, 2008).

Diante desse cenário, por razões sejam econômicas, sejam ambientais, ou mesmo devido ao crescimento dos sistemas de produção de base agroecológica, em que o uso dos formicidas químicos convencionais é proibido, tem crescido a demanda do setor agroflorestal por tecnologias alternativas para o controle de formigas-cortadeiras (ARAÚJO et al., 2003). O controle mecânico é uma dessas alternativas, e uma das técnicas desse controle é o uso de barreiras físicas que protegem a planta do ataque das formigas cortadeiras, por meio do impedimento do acesso delas à parte aérea da planta, onde se localizam as principais partes atacadas por essas formigas, como folhas, flores e/ou frutos. Essas barreiras são também conhecidas como dispositivos antiformigas (JUSTI JÚNIOR et al., 1996; JACCOUD, 2000; ARAÚJO et al., 2003).

Diferentes tipos e modelos de barreiras físicas já foram desenvolvidos e muitos foram patenteados, entre eles os cones confeccionados com plástico firme cortados em círculos geralmente de $20 \mathrm{~cm}$ de diâmetro, que são presos ao caule das plantas em posição invertida, isto é, com seu vértice voltado para cima, sendo popularmente também denominados de "saia" ou "chapéu chinês" (JACCOUD, 2000; MORESSI et al., 2007; LIMA, 2011). Todavia, embora seja uma técnica antiga e de eficiência comprovada na prática contra as formigas-cortadeiras, poucos estudos registram o nível de eficiência desses cones, bem como se características como o diâmetro do círculo podem interferir nessa eficiência, e quais comportamentos das formigas na presença dessas barreiras podem explicar o funcionamento das mesmas (JACCOUD, 2000; ARAÚJO et al., 2003; MORESSI et al., 2007).

Nesse contexto, o presente trabalho teve o objetivo de avaliar a eficiência e o princípio de funcionamento de cones confeccionados artesanalmente a partir de lâmina de acetato, em dois tamanhos de geratriz, como barreiras físicas contra o ataque de formigas-cortadeiras em condições de campo.

\section{MATERIAL E MÉTODOS}

\section{Local de estudo}

O trabalho foi conduzido em quintal residencial naturalmente infestado por formigas cortadeiras localizado no município de Petrópolis (22³3'45" S de latitude e $43^{\circ} 11^{\prime} 15^{\prime}$ " W de longitude, e $838 \mathrm{~m}$ de altitude), na região serrana do estado do Rio de Janeiro. O clima é caracterizado como tropical de altitude, com verões úmidos e invernos secos, com temperaturas geralmente amenas (média anual de aproximadamente $19{ }^{\circ} \mathrm{C}$, com temperatura média de $23{ }^{\circ} \mathrm{C}$ no mês mais quente e de $15{ }^{\circ} \mathrm{C}$ no mês mais frio), e o índice pluviométrico é de aproximadamente $2.400 \mathrm{~mm}$ anuais.

\section{Primeiro experimento}

Esse experimento consistiu de três tratamentos: 1) pedaço de casca de laranja fixado em ramo de eucalipto protegido com barreira física cônica de $5,4 \mathrm{~cm}$ de geratriz (cone pequeno); 2) pedaço de casca de laranja fixado em ramo de eucalipto protegido com barreira física cônica de 10,8 cm de geratriz (cone grande); e 3) pedaço de casca de laranja em ramo de eucalipto sem barreira física (controle), com dez repetições/tratamento. 
As barreiras físicas foram confeccionadas artesanalmente com lâminas de acetato (transparências de impressora jato de tinta de tamanho A4), que foram cortadas em círculos de dois tamanhos: 10,8 e $21,6 \mathrm{~cm}$ de diâmetro. Um corte reto foi feito nesses círculos, com o auxílio de uma tesoura, no sentido do raio da circunferência, e um corte circular com cerca de $1 \mathrm{~cm}$ de diâmetro foi feito no centro dos mesmos, para permitir que os círculos envolvessem o ramo de eucalipto e fossem ajustados conforme a espessura dos ramos. Os círculos foram colocados nos ramos a cerca de $30 \mathrm{~cm}$ do solo, e suas laterais foram presas com grampos galvanizados 26/6 e fita adesiva, para reforçar sua fixação nos ramos, obtendo-se, no final, o formato de cone com 5,4 e 10,8 cm de geratriz (cone pequeno e cone grande, respectivamente), com o vértice voltado para cima. $\mathrm{O}$ reforço com fita adesiva tende a impedir uma tendência normal do cone de ficar com sua superfície encostada no ramo. Dessa forma, a fita mantém apenas o vértice do cone em contato com o ramo e a sua borda completamente afastada do ramo.

Os pedaços de casca de laranja doce (Citrus sinensis (L.) Osbeck, variedade pera) apresentavam uma área de $6,0 \mathrm{~cm}^{2}(2,0 \times 3,0 \mathrm{~cm})$, sendo colocado um pedaço na extremidade superior de cada ramo de eucalipto, constituindo assim a parcela experimental (Figura 1). Os ramos de eucalipto apresentavam $70 \mathrm{~cm}$ de comprimento e foram fixados no solo em posição vertical. A distância entre as estacas foi de cerca de 30 a $50 \mathrm{~cm}$ e toda a área experimental ocupada com estacas tinha 15 metros quadrados. A casca de laranja foi usada como isca atrativa (fonte de alimento), sendo composta pelo flavedo (parte amarela) e albedo (parte branca). Este último se constitui na parte mais atrativa às formigas-cortadeiras (CHERRETT; SEAFORTH, 1970) e pode ser facilmente cortado pelas operárias forrageadoras, permitindo assim melhor observação dos cortes efetuados. O flavedo foi mantido para proporcionar melhor fixação das iscas nos ramos.

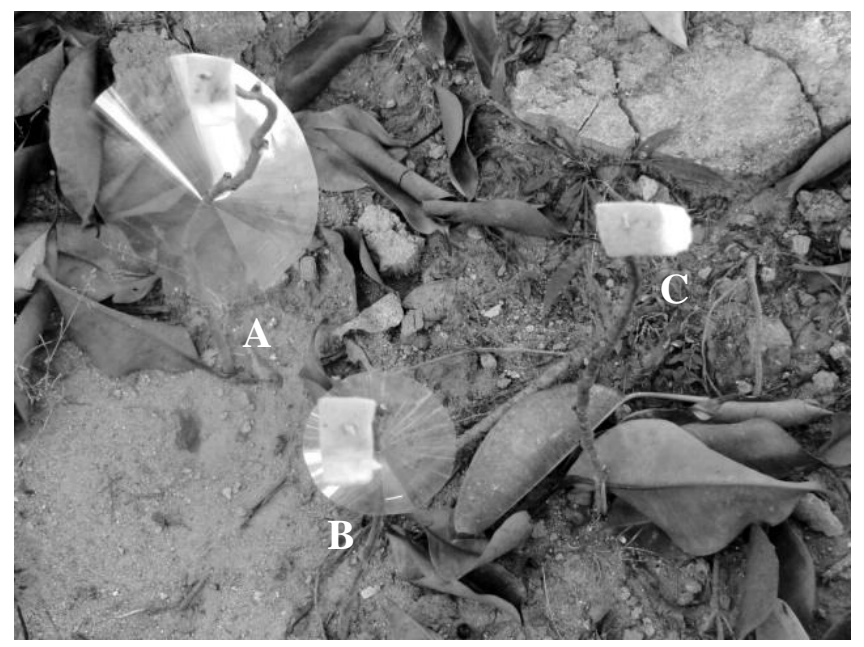

Figura 1. Parcelas experimentais: ramos de eucalipto com isca atrativa (pedaço de casca de laranja) na extremidade superior dos mesmos (A: tratamento com cone grande; B: tratamento com cone pequeno; C: tratamento controle, sem cone).

Figure 1. Experimental units: eucalypt branches with attractant bait (slices of orange peel) in their top (A. treatment with big cone; B. treatment with small cone; C: control treatment, without cone).

O experimento foi conduzido no período de 14 de fevereiro a 29 de março de 2011, quando se procedeu às observações diárias das iscas, para verificar a visitação de formigas-cortadeiras e as suas possíveis tentativas de ataque às iscas. Essas observações foram realizadas em dois períodos $(14 \mathrm{a}$ $24 / 02 / 2011$ e 24/02 a 29/03/2011), que findaram quando as iscas do tratamento controle tiveram $100 \%$ de sua área removida pelas formigas cortadeiras. Findo o primeiro período, os cones foram retirados e novamente colocados numa nova casualização. No experimento, um total de 15 ramos de eucalipto foram usados, sendo cinco ramos de eucalipto por tratamento, correspondendo às parcelas 1 a 5 no primeiro período de observação e às parcelas 6 a 10 no segundo período. Como foram dois períodos de observação, houve, portanto, um total 10 repetições por tratamento.

A porcentagem de área removida das iscas pelas formigas cortadeiras foi determinada diariamente a partir do segundo dia após a instalação do experimento. A área das iscas foi 
imaginariamente dividida em quatro quadrantes, para a determinação da porcentagem da área cortada e removida. Sendo assim, 1/4, 2/4, 3/4 e 4/4 de isca cortada representaram o equivalente a $25 \%, 50 \%, 75 \%$ e $100 \%$ de área removida pelas formigas, respectivamente. Quando as iscas apresentavam mofo, eram trocadas, tomando-se o cuidado de substituir por isca do mesmo tamanho, ou seja, uma isca mofada com $50 \%$ de corte era trocada por uma isca nova com o tamanho dos $50 \%$ da isca não cortada.

Para avaliar a significância da diferença entre os tratamentos, as frequências observadas de iscas atacadas e não atacadas pelas formigas-cortadeiras nas dez repetições de cada tratamento foram analisadas pela Prova Exata de Fisher (SIEGEL, 1975). Esse teste estatístico não paramétrico determina se dois grupos independentes (isto é, no presente estudo, comparou-se o cone pequeno com o controle; o cone grande com o controle e, depois, os dois cones entre si) diferem significativamente ou não na proporção em que eles se enquadram em duas classificações (isto é, no presente estudo, iscas atacadas e não atacadas), por meio da determinação da probabilidade da ocorrência dos valores observados. Portanto, testou-se a hipótese de nulidade $\left(\mathrm{H}_{0}\right)$ de que os dois grupos independentes acusam proporções iguais nas duas classificações.

Essa probabilidade foi calculada a partir das frequências dos valores observados e foram representadas em uma tabela de contingência $2 \times 2$. Essa probabilidade referiu-se à razão do produto dos fatoriais dos quatro totais marginais das frequências observadas na referida tabela pelo fatorial do número total de casos independentes observados e dos fatorais das frequências observadas dispostas nas células da tabela, sendo usada a seguinte equação (SIEGEL, 1975): P = (G!H!E!F!) / (I!A!B!C!D!), em que E, F, $\mathrm{G}$ e $\mathrm{H}=$ totais marginais das frequências observadas $(\mathrm{A}+\mathrm{C}, \mathrm{B}+\mathrm{D}, \mathrm{A}+\mathrm{B}$ e $\mathrm{C}+\mathrm{D}$, respectivamente); $\mathrm{I}=$ número total de casos independentes observados; e A, B, C e D = frequências observadas.

Foi usado o nível de $5 \%(\alpha=0,05)$ para determinar a significância da diferença entre os dois grupos independentes (isto é, no presente estudo, cone pequeno com o controle, cone grande com o controle e os dois cones entre si). $\mathrm{H}_{0}$ foi rejeitada quando os valores observados foram de magnitude tal que a probabilidade associada a sua ocorrência, sob $\mathrm{H}_{0}$, não foi superior a $\alpha=0,05$.

\section{Segundo experimento}

Foi instalado no dia 25 de fevereiro de 2011, em uma raiz de uma planta epífita da família Araceae, que apresentava um fluxo naturalmente intenso de formigas-cortadeiras nos dois sentidos, ou seja, subindo e descendo pela raiz. Inicialmente, foi colocado um cone grande acima de um pequeno na raiz, com o objetivo de bloquear a descida das formigas para o pequeno. Dessa forma, foi possível observar apenas o fluxo ascendente de formigas para o cone pequeno. Posteriormente, foi colocado um cone grande abaixo do cone pequeno e a raiz ficou com três cones, na ordem, de cima para baixo, grande, pequeno e grande (Figura 2), para que fosse possível observar apenas o comportamento das formigas que subiam até encontrar o cone grande, por um período de 3 horas. Todos os cones foram instalados com o vértice voltado para cima e com distância de aproximadamente $40 \mathrm{~cm}$ um do outro. Esse experimento foi feito em local a $200 \mathrm{~m}$ de distância do primeiro experimento.

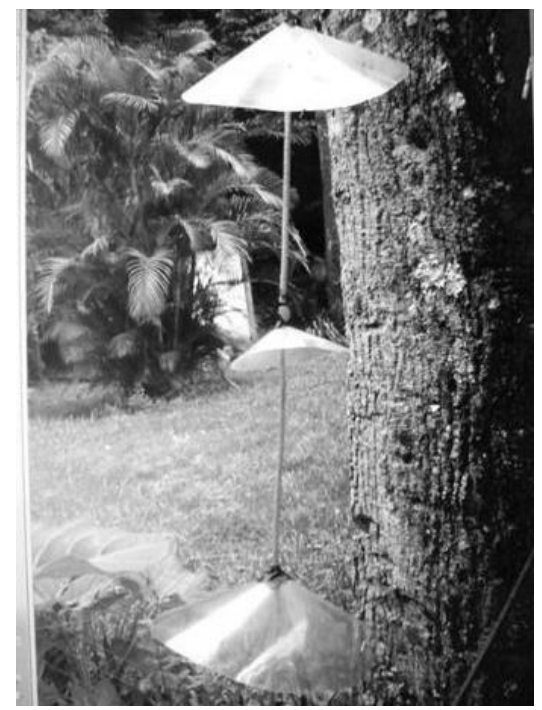

Figura 2. Vista geral do segundo experimento após a instalação dos três cones na raiz de Araceae.

Figure 2. Overview of the second experiment after the installation of the three cones on the Araceae root. 


\section{Identificação das espécies de formigas}

Espécimes das formigas-cortadeiras que forragearam as iscas e as que transitavam pela raiz da Araceae foram coletados, sendo armazenados em frascos de vidro com álcool $70 \%$ e enviados ao Departamento de Biologia Animal do Instituto de Biologia da Universidade Federal Rural do Rio de Janeiro (UFRRJ), para identificação específica por especialista no grupo.

\section{RESULTADOS E DISCUSSÃO}

\section{Espécies de formigas-cortadeiras forrageadoras}

Duas espécies de quenquém foram coletadas forrageando as iscas do experimento 1 , sendo identificadas como Acromyrmex niger (F. Smith), cujos espécimes foram coletados no início do experimento, e Acromyrmex disciger (Mayr), coletada no final do experimento. Provavelmente, essa distribuição temporal possa ser resultante do comportamento dessas formigas em evitar a competição interespecífica. De acordo com Gonçalves (1961), A. disciger é comum e ativa em locais onde não há presença de outras formigas-cortadeiras, quando se torna normalmente prejudicial, o que sugere ser uma pobre competidora. De acordo com Traniello (1989), os principais determinantes ecológicos das estratégias de forrageio das formigas são a distribuição dos recursos no tempo e no espaço e sua quantidade, tolerâncias fisiológicas, o risco de predação e a competição. Na raiz de Araceae, apenas $A$. niger foi identificada.

A. disciger é conhecida vulgarmente como quenquém-mirim e já está registrada para o estado do Rio de Janeiro, além de Santa Catarina e São Paulo. Silva et al. (1968) registram que essa espécie ocorre comumente em hortas e jardins. É considerada uma praga em potencial, pois corta uma variedade de plantas cultivadas, como hortaliças, entre elas, mandioca e couve, diversas árvores frutíferas (laranjeira, pessegueiro e videira, por exemplo) e roseira (GONÇALVES, 1961; SILVA et al., 1968; PIKART et al., 2010). Essa espécie constrói seu ninho coberto com palha, pouco saliente e parcialmente enterrado, e seus carreiros são subterrâneos e longos (GALLO et al., 2002).

A. niger já foi registrada no estado do Rio de Janeiro, além de Santa Catarina, São Paulo, Ceará, Espírito Santo, Paraná e Minas Gerais. É vulgarmente conhecida pelos nomes de formiga-mineira-deduas-cores, formiga-mineira-de-petrópolis, quenquém-mineira-de-petrópolis, quenquém e quenquémmineira-de-duas-cores (SILVA et al., 1968). Essa espécie corta folhas de hortaliças (couve e repolho), de diversas árvores frutíferas (laranjeira, macieira, pereira e pessegueiro) (SILVA et al., 1968) e de essências florestais (ANJOS et al., 2008). Os seus ninhos apresentam apenas uma panela e são de difícil localização. A terra escavada para a construção da panela e das galerias é distribuída de tal forma que não há formação de montículos na superfície, sendo de controle difícil devido aos poucos olheiros (um a dois), os quais não são facilmente localizados (GALLO et al., 2002).

As características dos ninhos e carreiros construídos por essas quenquéns as tornam de difícil localização, de modo que a destruição dos ninhos ou mesmo o uso de isca ou pó formicida tornam-se métodos de difícil aplicação, sugerindo que outros métodos de controle, como as barreiras físicas, devem ser mais eficientes, dispensando a necessidade de encontrar os ninhos.

Ambas as espécies de quenquéns já foram constatadas forrageando folhas e, por vezes, pétalas de laranjeiras, mas não há registro de ataque delas a frutos (casca e/ou polpa) de Citrus sp. (SILVA et al., 1968). As observações de corte e transporte de fragmentos das iscas atrativas, ou seja, das cascas de laranja, por A. disciger corroboram as de Forti et al. (2006), que reportaram o corte e/ou transporte de fragmentos de casca seca de frutos de dicotiledônea por essa espécie de quenquém, embora não tenha identificado a espécie botânica desse fruto.

\section{Primeiro experimento}

Nos três primeiros dias após a instalação do experimento (15, 16 e 17/02/2011), não foi observado nenhum corte nas iscas atrativas dos três tratamentos ou a presença de formigas cortadeiras. Todavia, no quarto dia, quatro parcelas do tratamento controle (sem barreira física) e duas parcelas do tratamento com cone pequeno (barreira artesanal cônica de 5,4 $\mathrm{cm}$ de geratriz) estavam com as iscas cortadas por formigas (Tabela 1). No controle, as iscas de apenas duas parcelas tiveram sua área totalmente removida apenas no último dia do primeiro período de observação, e a isca da parcela 5 teve $100 \%$ de sua área removida no sétimo dia após a instalação do experimento. No tratamento com cone 
pequeno, a área removida da isca foi de apenas $10 \%$ numa das parcelas e se manteve inalterada até o final do primeiro período de observação. Na outra parcela, $100 \%$ da isca foram removidos nos quatro primeiros dias de observação. Todas as demais parcelas experimentais permaneceram não forrageadas durante esse primeiro período de avaliação. Dessa forma, todas as cinco parcelas sem cone e duas das cinco parcelas com cone pequeno foram forrageadas no primeiro período de observação, enquanto que as cinco parcelas com cone grande não foram forrageadas.

Tabela 1. Área removida das iscas atrativas por Acromyrmex spp. nas parcelas experimentais forrageadas do tratamento controle (sem cone) e do tratamento com cone pequeno $(5,4 \mathrm{~cm}$ de geratriz) durante o primeiro período de observação (14 a 24 de fevereiro de 2011). Petrópolis, RJ, Brasil.

Table 1. Removed area of the attractant baits by Acromyrmex spp. in the foraging experimental units of the control treatment (without cone) and the treatment with small cone $(5.4 \mathrm{~cm}$ of generatrix) during the first period of observation (February 14 to 24, 2011). Petrópolis, RJ, Brazil.

\begin{tabular}{|c|c|c|c|c|c|c|c|c|}
\hline \multirow{2}{*}{ Tratamento } & \multirow{2}{*}{ Parcela } & \multicolumn{7}{|c|}{ Área removida (\%) da isca atrativa por dia observado } \\
\hline & & 18/fev & 19/fev & 20/fev & 21/fev & 22/fev & 23/fev & 24/fev \\
\hline \multirow[t]{5}{*}{ Controle } & 1 & 0 & 0 & 0 & 0 & 50 & 50 & 100 \\
\hline & 2 & 100 & - & - & - & - & - & - \\
\hline & 3 & 20 & 50 & 50 & 50 & 90 & 90 & 100 \\
\hline & 4 & 100 & - & - & - & - & - & - \\
\hline & 5 & 20 & 50 & 50 & 100 & - & - & - \\
\hline \multirow[t]{2}{*}{ Cone pequeno } & 3 & 10 & 10 & 10 & 10 & 10 & 10 & 10 \\
\hline & 4 & 50 & 100 & - & - & - & - & - \\
\hline
\end{tabular}

Observou-se a presença de formiga em atividade até mesmo durante o dia, tentando cortar o flavedo de uma isca do tratamento com cone pequeno (Figura 3), que, no final do primeiro período de observação, acabou tento $100 \%$ de sua área removida. O padrão de forrageio diurno também foi registrado para outras espécies de Acromyrmex: A. striatus (Roger) e A. hispidus Santschi, na Argentina (BRENER; PROTOMASTRO, 1992).

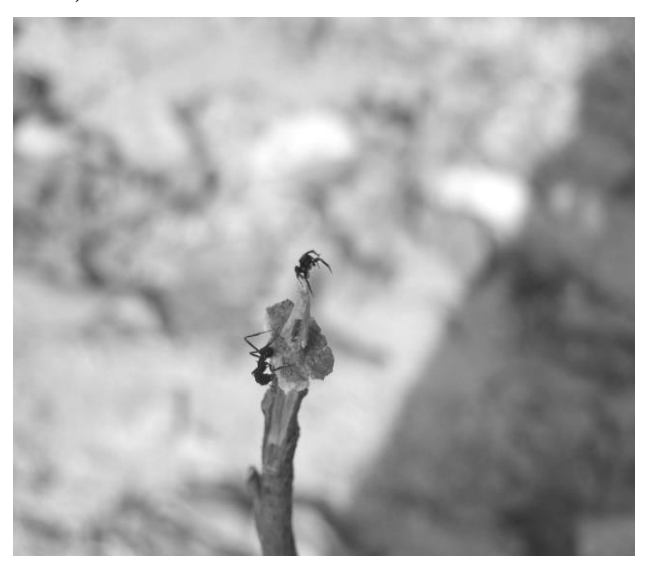

Figura 3. Formiga tentando cortar o flavedo da isca atrativa fixada no topo do ramo de eucalipto do tratamento com cone pequeno. Petrópolis, RJ, Brasil.

Figure 3. Ant trying to cut the flavedo of the attractant bait fixed at the top of the eucalypt branch of the treatment with small cone. Petrópolis, RJ, Brazil.

A visualização da formiga sobre a isca protegida pelo cone pequeno já comprova que ela conseguiu transpor a barreira física. O comportamento dessa formiga foi observado. Ela ficou mais de meia hora tentando separar um pedaço da isca, provavelmente pela dificuldade de cortá-la, talvez porque a isca já se encontrava ressecada e sem o albedo. Dessa forma, o corte da isca progredia com muita dificuldade. Finalmente, a formiga parou de cortar a isca e caminhou no ramo, dirigindo-se para baixo, em direção ao cone. Assim que chegou ao cone, andou pela superfície superior próxima ao centro e 
depois voltou a subir até o meio do ramo. Em seguida retornou ao cone, mas voltou novamente a subir pelo ramo até seu topo, sem tentar cortar novamente a isca. Depois retornou ao cone, quando então caminhou sobre a superfície superior até a borda e tentou passar para a superfície inferior do cone. A formiga caminhou preferencialmente pela borda do cone. Por várias vezes ela andou pela superfície superior até atingir a borda e, outras vezes, andou pela superfície inferior, mas, nesse último caso, sempre bem próxima da borda. Após repetir por seis vezes subidas e descidas, atingindo ao máximo a superfície inferior do cone próxima a sua borda, a formiga finalmente alcançou o ramo de eucalipto na parte inferior do cone e, de uma só vez, caminhou sobre o ramo em direção ao solo, abandonando-o, não voltando mais para o ramo e, portanto, desistindo de terminar de cortar a isca. Como $100 \%$ dessa isca foram removidos nos dias seguintes, provavelmente esta ou outras formigas devem ter voltado a forragear a mesma isca.

Apesar de as iscas protegidas com o cone grande não terem sofrido qualquer ataque de formiga durante o primeiro período de observação, a tentativa de forrageio nessas parcelas ocorreu, porque foi possível observar a subida de formigas-cortadeiras pelo ramo de eucalipto em algumas parcelas experimentais desse tratamento. No entanto, quando tocavam o cone grande, as formigas voltavam ao solo, não voltando a subir, abandonando de vez as parcelas.

A partir das observações das reações comportamentais das formigas na presença dos cones, os primeiros questionamentos que poderiam ser feitos são: por que a formiga explorou tanto a superfície superior do cone, como caminhou muitas vezes pela borda? Por que, ao encontrar o ramo e retornar ao solo, ela não retornou mais para aquele ramo, pelo menos nos momentos seguintes ao abandono do ramo? Uma hipótese para explicar o motivo dessa exploração intensa da borda do cone é a seguinte: na natureza, se uma formiga está em uma folha grande, ela pode percorrer a borda e, assim, logo achará o pecíolo e, na sequência, o caule da planta forrageada, encontrando, assim, a saída para o solo. Talvez o comportamento de seguir pela borda seja mais vantajoso do que percorrer caminhos lineares ou erráticos pelo limbo da folha, uma vez que a borda, na grande maioria das folhas, leva ao pecíolo, enquanto que o caminho pelo limbo pode resultar num gasto maior de tempo até encontrar o pecíolo.

Jaccoud (2000) registra algumas das reações comportamentais das formigas-cortadeiras quando em contato com as barreiras físicas, tais como a tentativa de cortar e destruir a barreira, empurrar umas às outras para forçar de algum modo a passagem e, entre outras possibilidades, procurar por pontos vizinhos de acesso à planta de sua escolha. Nenhuma dessas reações foi exibida pelas formigas quando observadas em contato com as barreiras cônicas avaliadas no presente estudo.

No segundo período de observação, apenas as iscas do controle sofreram o ataque de formigascortadeiras. Logo no dia seguinte após o início desse período, a isca da parcela 9 teve $60 \%$ de sua área removidos por essas formigas, sendo totalmente removida no dia subsequente, enquanto que o ataque às demais iscas ocorreu somente a partir do quinto dia do início desse período (Tabela 2). Nessa ocasião, ocorreu a remoção de $50 \%$ da isca da parcela 8 , e as iscas de três parcelas não foram atacadas pelas formigas. Dessas três parcelas, a remoção total da isca da parcela 6 ocorreu aos 29 dias após o início do segundo período de observação, e quatro dias após esse evento, 100\% das iscas foram removidas nas outras duas parcelas.

A remoção total das iscas pelas quenquéns confirma a atratividade do albedo da casca de laranja, conforme salientado por Cherrett e Seaforth (1970), os quais verificaram que cinco substâncias químicas presentes no albedo da casa de pomelo (Citrus paradisi Macf.) são arrestantes para Acromyrmex octospinosus (Reich). Todavia, esses autores tiveram evidências da existência de substâncias repelentes no flavedo de pomelo, o que possivelmente não ocorre nessa parte da casca dos frutos da variedade Pera de $C$. sinensis, visto que não só o albedo, como também o flavedo das iscas do controle, incluindo as do tratamento com cone pequeno, foram removidas por A. disciger e A. niger. É também possível que as substâncias químicas existentes nessa região das laranjas da variedade utilizada não possuam efeito repelente para as duas espécies de quenquéns que forragearam as iscas atrativas no presente estudo.

O resultado da Prova Exata de Fisher mostrou que os tratamentos com cone pequeno $(5,4 \mathrm{~cm}$ de geratriz) e cone grande $(10,8 \mathrm{~cm}$ de geratriz) diferem significativamente do controle (sem cone) na proporção de iscas atrativas atacadas e não atacadas pelas formigas-cortadeiras. Os tratamentos com as barreiras físicas cônicas apresentaram significativamente maior proporção de iscas sem ataque dessas formigas do que o controle $(\mathrm{P}=0,00036$, para a comparação entre controle e cone pequeno, e $\mathrm{P}=0,0000054$, para a comparação entre controle e cone grande, considerando $\alpha=0,05$ ). Contudo, na comparação entre os dois tamanhos de barreira cônica não houve diferença significativa $(P=0,2368$, seja $\alpha=0,05$ ). Pode-se inferir, portanto, que as barreiras físicas em formato de cone foram eficientes contra 0 ataque das duas espécies de Acromyrmex. Futuros estudos com maior tamanho amostral talvez possam detectar diferença significativa entre esses dois tamanhos de barreiras cônicas. 
Tabela 2. Área removida das iscas atrativas por Acromyrmex spp. nas parcelas experimentais forrageadas do tratamento controle durante o segundo período de observação ( 24 de fevereiro a 29 de março de 2011). Petrópolis, RJ, Brasil.

Table 2. Removed area of the attractant baits by Acromyrmex spp. in the foraging experimental units of the control treatment during the second period of observation (February 24, 2011 to March 29, 2011). Petrópolis, RJ, Brazil.

\begin{tabular}{lccccc}
\hline \multirow{2}{*}{ Dia da observação } & \multicolumn{6}{c}{ Área removida $(\%)$ da isca atrativa em cada parcela } \\
\cline { 2 - 6 } & $\mathbf{6}$ & $\mathbf{7}$ & $\mathbf{8}$ & $\mathbf{9}$ & $\mathbf{1 0}$ \\
\hline $25 / \mathrm{fev}$ & 0 & 0 & 0 & 60 & 0 \\
$26 / \mathrm{fev}$ & 0 & 0 & 0 & 100 & 0 \\
$01 / \mathrm{mar}$ & 0 & 0 & 50 & - & 0 \\
$22 / \mathrm{mar}$ & 20 & 0 & 80 & - & 0 \\
$23 / \mathrm{mar}$ & 50 & 0 & 100 & - & 0 \\
$24 / \mathrm{mar}$ & 80 & 0 & - & - & 0 \\
$25 / \mathrm{mar}$ & 100 & 0 & - & - & 0 \\
$26 / \mathrm{mar}$ & - & 20 & - & - & 0 \\
$27 / \mathrm{mar}$ & - & 50 & - & - & 20 \\
$28 / \mathrm{mar}$ & - & 80 & - & - & 60 \\
$29 \mathrm{mar}$ & - & 100 & - & - & 100 \\
\hline
\end{tabular}

Neste experimento, o cone grande apresentou $100 \%$ de eficiência na proteção contra as quenquéns, ou seja, nenhuma das dez iscas oferecidas foi atacada pelas formigas. O cone pequeno teve uma eficiência de $80 \%$, pois oito das dez das iscas com esse cone não sofreram o ataque, enquanto que o controle apresentou $0 \%$ de eficiência, com todas as suas dez iscas atacadas por formigas.

Esses resultados corroboram, em parte, as recomendações de Jaccoud (2000), de que as barreiras físicas no formato de cone com vértice para cima, ou seja, do tipo "saia", apresentam grande eficiência na proteção de plantas contra formigas-cortadeiras e que o cone deve ser cortado no tamanho de $20 \mathrm{~cm}$ de diâmetro, uma vez que os cones avaliados no presente estudo apresentam tamanho de 10,8 e 21,6 cm, sendo que o último protegeu $100 \%$ das iscas atrativas contra o ataque das quenquéns. Todavia, Moressi et al. (2007) verificaram que cones de plástico grosso de $20 \mathrm{~cm}$ de diâmetro apresentaram apenas $50 \%$ de eficiência na proteção de mudas de espécies arbóreas nativas contra saúvas (Atta laevigata F. Smith.), as quais foram capazes de causar mais de $80 \%$ de desfolhamento das mudas sem qualquer tipo de barreira física.

\section{Segundo experimento}

Observou-se que as quenquéns que desciam pela raiz não foram capazes de transpor o cone grande, sendo que no máximo exploravam a borda do cone. O cone pequeno, posicionado abaixo do grande, foi capaz de evitar a passagem das quenquéns que subiam pela raiz por apenas dez minutos, portanto, perdendo totalmente sua eficiência após esse pequeno período de tempo. Assim, após esse período, colocou-se outro cone grande abaixo do cone pequeno. $\mathrm{O}$ comportamento das formigas frente à barreira cônica permitiu entender a maior eficência do cone com geratriz maior. Apesar do intenso fluxo de formigas subindo pela raiz da Araceae, apenas uma única formiga conseguiu transpor o cone grande colocado abaixo do cone pequeno durante as 3 horas de observação. Observou-se que as formigas que subiam pela raiz a partir do solo exploram a superfície inferior do cone, sendo que a maioria delas percorreu preferencialmente a borda do mesmo. Após explorar mais intensamente essa parte do cone, as formigas retornavam ao solo. Dessa forma, pode-se inferir que, quanto maior a geratriz do cone, menor será a probabilidade de a formiga atingir as partes da planta acima dessa barreira. Segundo o nosso conhecimento, esses comportamentos ainda não tinham sido descritos, e uma possível explicação para a preferência pela borda do cone pelas quenquéns é agir como se seguissem pela borda de uma folha, a qual pode ser o caminho mais eficiente para localizar o seu pecíolo e, na sequência, o caule e retornar ao solo. Os resultados obtidos ainda sugerem que mesmo depois de a planta ser infestada pelas formigas, o cone grande pode ser eficiente em conter as formigas em seu acesso à sua parte aérea, mas isso dependerá também da intensidade de ataque.

A hipótese formulada na observação do primeiro experimento permaneceu válida no segundo experimento, ou seja, existe um comportamento das formigas de percorrerem preferencialmente a borda 
do cone. Dessa forma, a hipótese segundo a qual as formigas estariam percorrendo a margem do cone como se fosse a margem de uma folha foi testada da seguinte forma: formigas quenquéns foram coletadas e colocadas sobre folhas de diferentes plantas. Assim, foi possível observar que elas realmente procuravam preferencialmente a borda e caminhando sobre ela acabavam encontrando o pecíolo, para poderem sair da folha. Esse procedimento foi repetido por cinco vezes e o mesmo comportamento foi observado. Assim, a hipótese formulada não pôde ser rejeitada.

As diferenças de eficiência dos cones entre os dois experimentos talvez possa ser explicada pela intensidade muito maior de fluxo de formigas no segundo experimento. Essa maior intensidade pode ter sido a causa da perda da eficiência do cone pequeno.

O conjunto dos resultados não indica que a barreira cônica, mesmo com a maior geratriz testada, seja capaz de garantir controle com 100\% de eficiência, uma vez que a barreira não impede a passagem, mas apenas reduz a probabilidade de as formigas encontrarem a parte do caule acima da barreira.

\section{CONCLUSÕES}

- A barreira física artesanal cônica confeccionada com lâmina de acetato com 5,4 ou $10,8 \mathrm{~cm}$ de geratriz é capaz de impedir, pelo menos parcialmente, o acesso das quenquéns à fonte de alimento localizada acima da mesma, porém, tende a ser mais eficiente quanto maior é o tamanho da geratriz.

- O princípio de funcionamento da barreira cônica contra as quenquéns fundamenta-se no comportamento dessas formigas de tenderem a explorar preferencialmente a borda do cone, de modo que quanto maior for sua geratriz, menor é a probabilidade dessas formigas de transpor a barreira física e alcançar a parte aérea da planta.

\section{AGRADECIMENTOS}

A CAPES (Coordenação de Aperfeiçoamento de Pessoal de Ensino Superior), pela concessão da bolsa de mestrado ao primeiro autor. Os autores também são grato, ao Prof. Dr. Antônio José Mayhé Nunes (Depto. Biologia Animal/IB/UFRRJ), pela identificação das espécies de quenquéns.

\section{REFERÊNCIAS}

ANJOS, N.; ARNHOLD, A.; CORRÊA, G. V. V.; STUMPF, K. Árvores e formigas-cortadeiras (Hymenoptera: Formicidae) em Viçosa, Minas Gerais. Revista Trópica - Ciências Agrárias e Biológicas, Chapadinha, v. 2, p. 11 - 16, 2008.

ANTUNES, E. C.; DELLA LUCIA, T. M. C. Consumo foliar em Eucalyptus urophylla por Acromyrmex laticeps nigrosetosus Forel (Hymenoptera-Formicidae). Ciência e Agrotecnologia, Lavras, v. 23, p. 208 211, 1999.

ARAÚJO, M. S.; DElla LUCIA, T. M. C.; SOUZA, D. J. Estratégias alternativas de controle de formigas-cortadeiras. Bahia Agrícola, Salvador, v. 6, p. 71 - 74, 2003.

BOARETTO, M. A. C.; FORTI, L. C. Perspectiva no controle de formigas-cortadeiras. Série Técnica IPEF, São Paulo, v. 11, n. 30, p. 31 - 46, 1997.

BRENER, A. G. F.; PROTOMASTRO, J. Patrones forrajeros de dos especies simpaticas de hormigas cortadora de hojas (Attini, Acromyrmex) en un bosque subtropical seco. Ecotropicos, Mérida, v. 5, p. 32 43, 1992.

CHERRETT, J. M.; SEAFORTH, C. E. Phytochemical arrestants for the leaf-cutting ants, Atta cephalotes (L.) and Acromyrmex octospinosus (Reich), with some notes on the ants' response. Bulletin of Entomological Research, London, v. 59, p. 615 - 625, 1970.

FORTI, L. C.; ANDRADE, M. L.; ANDRADE, A. P. P.; LOPES, J. F. S.; RAMOS, V. M. Bionomics and identification of Acromyrmex (Hymenoptera: Formicidae) through an illustrated key. Sociobiology, Chico, v. 48, p. 1 - 18, 2006. 
GALLO, D.; NAKANO, O.; SILVEIRA NETO, S.; CARVALHO, R. P. L.; BAPTISTA, G. C.; BERTI FILHO, E.; PARRA, J. R. P.; ZUCCHI, R. A.; ALVES, S. B.; VENDRAMIM, J. D.; MARCHINI, L. C.; LOPES, J. R. S.; OMOTO, C. Entomologia agrícola. Piracicaba: FEALQ, 2002. 920 p. (Biblioteca de Ciências Agrárias Luiz de Queiroz, 10).

GONÇALVES, C. R. O gênero Acromyrmex no Brasil (Hym. Formicidae). Studia Entomologica, Petrópolis, v. 4, p. 113 - 180, 1961.

JACCOUD, D. B. Formigas-cortadeiras: princípios de manejo integrado de áreas infestadas. Brasília: IBAMA, 2000. 60 p. (Série Meio Ambiente em Debate, 34).

JUSTI JÚNIOR, J.; IMINES, S. L.; BREGMANN, E. C.; CAMPOS-FARINHA, A. E. C.; ZORZENON, F. J. Barreiras físicas ou dispositivos antiformigas. In: Formigas cortadeiras. São Paulo: Instituto Biológico, 1996 (Boletim Técnico, 4). p. 15.

LIMA, J. E. O. Dispositivo protetor de troncos de plantas em geral. Disponível em: <http://www.patente sonline.com.br/dispositivo-protetor-de-troncos-de-plantas-em-geral-173346.html >. Acesso em: 12/01/2011.

LINK, H. M.; LINK, F. M.; LINK, D. Controle da formiga-preta-pastadeira, Acromyrmex crassispinus, com formicidas em pó. Ciência Florestal, Santa Maria, v. 10, p. 45 - 56, 2000.

MENDES FILHO, J. M. A. Ação danosa de pragas desfolhadoras sobre as florestas de Eucalyptus. Piracicaba: ESALQ/USP, 1981. 6 p. (Circular Técnica, 131).

MORESSI, M.; MORAES NETO, A.; CREPALDI, R. A.; CARBONARI, V.; DEMÉTRIO, M. F.; SILVESTRE, R. Eficiência do controle mecânico de formigas-cortadeiras (Atta laevigata) no reflorestamento com espécies nativas. O Biológico, São Paulo, v. 69, suplemento 2, p. 471 - 473, 2007.

NICKELE, M. A. Distribuição especial, danos e planos de amostragem de Acromyrmex crassispinus (Forel, 1909) (Hymenoptera: Formicidae: Myrmicinae) em plantios de Pinus taeda L. (Pinaceae). 111 f. Dissertação (Mestrado em Ciências Biológicas) - Universidade Federal do Paraná. Curitiba, 2008.

NICKELE, M. A.; REIS FILHO, W.; OLIVEIRA, E. B.; IEDE, E. T. Densidade e tamanho de formigueiros de Acromyrmex crassispinus em plantios de Pinus taeda. Pesquisa Agropecuária Brasileira, Brasília, v. 44, p. 347 - 353, 2009.

PIKART, T. G.; SOUZA, G. K.; PIKART, F. C.; RIBEIRO, R. C.; ZANUNCIO, J. C. Registro de Acromyrmex disciger (Hymenoptera: Formicidae) em Cinnamomum zeylanicum (Lauraceae) no município de Braço do Trombudo, Santa Catarina, Brasil. EntomoBrasilis, Vassouras, v. 3, p. 89 - 91, 2010.

SIEGEL, S. A prova exata de Fisher, p. 107 - 116. In: SIEGEL, S. Estatística não paramétrica (para as ciências do comportamento). São Paulo: McGraw-Hill, 1975. 350 p.

SILVA, A. G. D’A.; GONÇALVES, C. R.; GALVÃO, D. M.; GONÇALVES, A. J. L.; GOMES, J.; SILVA, M. N.; SIMINI, L. Quarto catálogo dos insetos que vivem nas plantas do Brasil, seus parasitos e predadores. Rio de Janeiro: Ministério da Agricultura, Departamento de Defesa e Inspeção Agropecuária. Parte 2, Tomo 1, 1968. 622 p.

SOUSA, T. G. Estudo da viabilidade técnica da implantação de uma empresa de elaboração de projetos na área de preservação ambiental e uso sustentável da madeira de lei em Brasília - DF. 2008. 87 f. Monografia (Graduação em Agronomia) - UPIS - Faculdades Integradas do Distrito Federal, Planaltina, 2008.

SOUZA-SIlVA, A.; ZANETTI, R.; CARVALHO, G. A.; SANTOS, A.; MATTOS, J. O. S. Preferência de formigas-cortadeiras por mudas de eucalipto pulverizadas ou imersas em soluções de extrato pirolenhoso em diferentes concentrações. Scientia Forestalis, Piracicaba, v. 67, p. 9 - 13, 2005.

TRANIEllo, J. F. A. Foraging strategies of ants. Annual Review of Entomology, Palo Alto, v. 34, p. 191 - 210, 1989.

ZANETTI, R.; ZANUNCIO, J. C.; VILELA, E. F.; LEITE, H. G.; JAFFÉ, K.; OLIVEIRA, A. C. Level of economic damage for leaf-cutting ants in Eucalyptus plantations in Brazil. Sociobiology, Chico, v. 42, p. $433-442,2003$. 